\title{
Erratum to: Grapevine phenology and climate change in Georgia
}

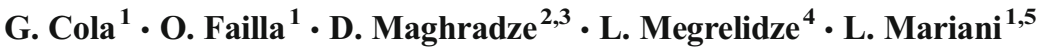

Published online: 8 December 2016

(C) ISB 2016

\section{Erratum to: Int J Biometeorol}

DOI 10.1007/s00484-016-1241-9

The acknowledgement was omitted from the original article.

\section{Acknowledgments}

This paper is one of the result of the activity of the Working Group 4 of the "Research Project on Georgian Grape and Wine Culture" promoted by the National Wine Agency of Georgia. We would like to express our sincere thanks to all the people involved in the COST ACTION FA1003
- Grapenet: East-west Collaboration for Grapevine Diversity Exploration and Mobilization of Adaptive Traits for Breeding, to the Hydrometeorology Department of the National Environmental Agency of Georgia and to the Georgian National Wine Agency.

Special thanks to the Scientific-Research Center of Agriculture and to the Research Institute of Viticulture and Oenology of the Agricultural University of Georgia for providing phenological data from their grapevine collections.

The online version of the original article can be found at http:// dx.doi.org/10.1007/s00484-016-1241-9.

G. Cola

gab.cola@gmail.com

1 Department of Agricultural and Environmental Sciences -

Production, Landscape, Agroenergy, University of Milan, 2, Via

Celoria, Milan 20133, Italy

2 Scientific-Research Center of Agriculture, 6, Marshal Gelovani Ave, Tbilisi 0159, Georgia

3 National Wine Agency of Georgia, 6, Marshal Gelovani Ave, 0159 Tbilisi, Georgia

4 National Environmental Agency of Georgia, 150 David Agmashenebeli ave., 0112 Tbilisi, Georgia

5 Lombard Museum of History of Agriculture, Piazza Bolognini 2, Sant'Angelo Lodigiano, LO 26866, Italy 